\title{
Role of Endothelin-1 Receptor Antagonist in Reducing Perioperative Pulmonary Arterial Hypertension after Surgical Correction of Ventricular Septal Defect
}

\author{
Rampada Sarker ${ }^{1}$, A.S.M.S. Islam ${ }^{1}$, S. C, Mandal ${ }^{1}$, Kazi Abul Hasan ${ }^{2}$, \\ Manoz Kumar Sarker ${ }^{1}$, ABM Abdus Salam ${ }^{3}$, Sk Abdur Razzaque ${ }^{3}$ \\ ${ }^{1}$ Department of Cardiac Surgery, ${ }^{2}$ Department of Paediatric Cardiac Surgery, ${ }^{3}$ Department of \\ Paediatric Cardiology, National Institute of Cardiovascular Diseases, Dhaka
}

\begin{abstract}
Key Words : Endothelin-1 receptor antagonist, Ambrisentan, Pulmonary arterial hypertension.
\end{abstract}

\begin{abstract}
:
Background: This study was designed to determine the role of oral ambrisentan, an endothelin-1 receptor, in reducing perioperative pulmonary arterial hypertension during surgical correction of ventricular septal defect.
\end{abstract}

Methods: This study was carried out among 54 patients of ventricular septal defect with pulmonary arterial hypertension undergoing surgical correction. The patients were divided into two groups; study group received oral ambrisentan, an endothelin-1 receptor antagonist peri-operatively, starting one week before surgery. Pulmonary arterial pressure was measured by echocardiography, cardiac catheterization and directly from pulmonary artery during surgical procedure.

Results: Pulmonary arterial pressure was reduced significantly in the group in which oral amrisentan was given perioperatively. There was further reduction of pulmonary arterial pressure at discharge from hospital and at one month follow-up.

Conclusion: Oral ambrisentan can reduce pulmonary arterial pressure perioperatively in patients underwent surgical correction of ventricular septal defect.

(Cardiovasc.j. 2016; 9(1): 55-59)

\section{Introduction:}

In patients with systemic-to-pulmonary shunts, the type and size of the defect as well as the magnitude of the shunt are risk factors for the development of pulmonary artery hypertension (PAH). ${ }^{1}$ Shear stress due to increased pulmonary blood flow and/ or increased pulmonary artery pressure appears to play a major role in the development of pulmonary vascular disease (PVR) related to congenital heart disease (CHD). ${ }^{2}$ Elevated pulmonary artery pressure in ventricular septal defect (VSD) is caused by pulmonary over circulation, pulmonary vasoconstriction and pulmonary vascular disease either alone or in combination. ${ }^{3} \mathrm{PAH}$ in pediatric patients with VSD remains one of the most important determinant of perioperative morbidity and mortality. ${ }^{4}$ Outcomes are significantly worse in patients with perioperative $\mathrm{PAH}$ and right ventricular (RV) failure prompting interest in the utility of newer therapies for this situation, including $\mathrm{PAH}$-specific therapies. ${ }^{5,6}$ While early surgical correction can prevent development of $\mathrm{PAH}$ in $\mathrm{CHD}, \mathrm{PAH}$ has become one of the leading but unresolved medical conditions that, like primary myocardial failure, significantly increases mortality and morbidity due to perioperative pulmonary hypertensive crisis. ${ }^{7,8}$ Endothelin-1, one of the most potent vasoconstrictors identified to date has been implicated in the pathophysiology of PAH. Endothelin-1 expression, production, and concentration in plasma and lung tissue are elevated in PAH patients and inversely correlated with prognosis. ${ }^{7}$ Endothelin contribute to PAH pathophysiology by promoting pulmonary smooth muscle cell hypertrophy, proliferation, and vasoconstriction through their interaction with endothelin receptor ( ETRs). ${ }^{9}$ Ambrisentan is a propanoic Acid-based endothelin receptor 1Aselective antagonist approved to once daily

Address of Correspondence: Prof. Rampada Sarker, Department of Cardiac Surgery, National Institute of Cardiovascular Diseases, Dhaka, Bangladesh. Email: rampada.heartsurgeon@gmail.com 
administration by FDA in 2007. ${ }^{8}$ The oral endothelin receptor antagonist Ambrisentan has been shown to improve the short and medium term course of adult PAH. ${ }^{10}$ We performed this study to search the role of amrisentan to reduce perioperative PAH in surgical correction of VSD.

\section{Methods:}

This was a prospective study, carried out in Department of Cardiac Surgery, National Institute of Cardiovascular Diseases (NICVD), Dhaka, Bangladesh, during January 2014 to December 2014 after approval by academic council of the institute. Total 54 patients were selected for surgical correction of VSD between age 2 to 15 years and were divided into two groups: Group- $\mathrm{A}=27$ patients with VSD with $\mathrm{PAH}$ who received oral amrisentan perioperatively, Group-B= 27 patients with VSD with PAH without oral ambrisentan. Patients associated with other congenital defect, valvular heart disease. PVR more than 8 wood unit $/ \mathrm{m}^{2}$ and patients with primary pulmonary hypertension (PPH) were excluded from the study. Written and informed consent taken from all patients under the study.

Preoperative assessment: Patients admitted in the cardiac surgery department, NICVD, fulfilling the inclusion and exclusion criteria were included in this study. Initially patients were selected after confirmation of diagnosis by echocardiogram detecting presence of VSD and PAH. Patients were divided into two groups. The Group-A consists of 27 patients who received ambrisentan two weeks before surgery. The other group that is Group-B did not receive ambrisentan and this group was considered as control. The dose of the drug ambrisentan was adjusted according the body weight of the patient. Patient weighing $<20 \mathrm{~kg}$ got $2.5 \mathrm{mg}$ of ambrisentan in two divided doses per day and patient weighing $>20 \mathrm{~kg}$ got $5 \mathrm{mg}$ of ambrisentan in two divided doses per day for at least two weeks before surgery.

Echocardiogram and recording of Pulmonary Arterial Systolic Pressure (PASP) was done before starting ambrisentan and one week and one month after operation which was performed in Department of Cardiology, NICVD by the same cardiologist. Cardiac catheterization was done in all patients at Department of Cardiology, NICVD to calculate PASP, PVR and reversibility for preoperative evaluation of patients.

\section{Surgical technique:}

All patients were operated as per local institutional protocol under cardio-pulmonary bypass and by median sternotomy. Per operatively PASP was recorded before establishment of cardiopulmonary bypass (CPB), just after surgical closure of VSD and after weaning from CPB with stable haemodynamics directly from pulmonary artery. Peropeartive aortic cross-clamp time (XCT) and extracorporeal circulation time (ECCT) were also recorded.

ICU management: All patients were taken into intensive care unit (ICU) after completion of operation and after extubation ambrisentan was continued. If prolong ventilation requires, ambrisentan was administered through Ryle's tube. In case of development of right ventricular (RV) failure (manifested by raised central venous pressure, hypotension, reduced SPO2) pulmonary vasodilators were used in both group of patients. Duration of ICU stay, ventilator support, development of RV failure, duration of hospital stay were recorded and compared between two groups.

Data were collected, recorded and interpretation was done by using SPSS version (Version-16). Preoperative data Age, sex, echocardiographic pulmonary artery systolic pressure(PASP), pulmonary artery(PA) pressure by Cardiac catheterization ; per-operative data extracorporeal circulation time(ECCT), aortic cross-clamp time(XCT), PA pressure measured directly from PA, and postoperatively PASP by echocardiography, mechanical ventilation time and ICU stay were collected.

\section{Results:}

There was no significant difference in preoperative variables between two groups( Table I). Peroperatively PA pressure was found to be significantly reduced before establishment of CPB, just closure of VSD on CPB and after weaning from CPB in Group-A (Table II) than Group-B. The XCT and ECCT were not significantly different (Table III); ICU stay and ventilation time were significantly less in group-A indicating less incidence of right ventricular failure. The PASP at $7^{\text {th }}$ postoperative day and at 1 month follow-up further reduced in group-A this reduction is significantly more than group-B. 
Table-I

Comparison of age and sex distribution between Group A and Group B $(n=54)$.

\begin{tabular}{|c|c|c|c|}
\hline \multirow[t]{2}{*}{ Age (years) } & \multicolumn{2}{|c|}{ Group } & \multirow[t]{2}{*}{ p-value } \\
\hline & Group A $(\mathrm{n}=27)$ & Group B $(\mathrm{n}=27)$ & \\
\hline $3-5$ & $9(33 \%)$ & $8(30 \%)$ & 0.324 \\
\hline $6-8$ & $8(30 \%)$ & $8(30 \%)$ & 0.314 \\
\hline $8-9$ & 10 (37\%) & $11(40 \%)$ & 0.401 \\
\hline Total & $27(100.0 \%)$ & $27(100.0 \%)$ & 0.312 \\
\hline Mean \pm SD & $5.30 \pm 1.787$ & $5.87 \pm 1.97$ & 0.360 \\
\hline
\end{tabular}

Table-II

Comparison of sex distribution between Groups $(n=54)$.

\begin{tabular}{|c|c|c|c|}
\hline \multirow[t]{2}{*}{$\overline{\operatorname{Sex}}$} & \multicolumn{2}{|c|}{ Group } & \multirow{2}{*}{$\begin{array}{c}\mathrm{p} \text {-value } \\
0.749\end{array}$} \\
\hline & Group A $\quad(n=27)$ & Group B $(n=27)$ & \\
\hline$\overline{\text { Female }}$ & $15(55.5 \%)$ & $13(48 \%)$ & \\
\hline Male & $12(44.5 \%)$ & $14(52 \%)$ & \\
\hline Total & $27(100.0 \%)$ & $27(100.0 \%)$ & \\
\hline
\end{tabular}

Table-III

Comparison of preoperative variables between groups $(n=54)$.

\begin{tabular}{lccc}
\hline Preoperative findings & \multicolumn{2}{c}{ Group } & \\
\cline { 2 - 3 } & $\begin{array}{c}\text { Group A } \\
\text { mean } \pm \text { SD }\end{array}$ & $\begin{array}{c}\text { Group B } \\
\text { mean } \pm \text { SD }\end{array}$ & p value \\
\hline PASP (mm of Hg) on echocardiogram & $70.96 \pm 10.80$. & $71.40 \pm 10.89$ & 0.895 \\
PASP on cardiac cath. & $71.33 \pm 10.69$ & $71.29 \pm 11.18$ & 0.629 \\
QP:QS in Cardiac cath. & $2.62 \pm 3.83$ & $1.90 \pm 0.13$ & 0.62 \\
PVR in cardiac cath & $4.66 \pm 0.83$ & $4.55 \pm 0.80$ & 0.94 \\
\hline
\end{tabular}

PVR= Pulmonary Vascular Resistance, Qp=Pulmonary circulation. Qs= Systemic circulation

Table-IV

Comparison of Peroperative PASP between groups ( $n=54)$.

\begin{tabular}{lrcc}
\hline Per-operative findings & \multicolumn{2}{c}{ Groups } & p value \\
\cline { 2 - 3 } & Group A & Group B & \\
& mean \pm SD & mean \pm SD & \\
\hline PA pressure (before establishment of CPB) & $59.55 \pm 11.16$ & $71.92 \pm 10.62$ & 0.002 \\
PA pressure (just after closure of VSD on CPB) & $45.49 \pm 9.46$ & $66.34 \pm 10.22$ & 0.001 \\
PA pressure (after weaning from CPB) & $40.49 \pm 10.33$ & $62.14 \pm 9.46$ & 0.001 \\
\hline
\end{tabular}

Table-V

Comparison of per-operative variables between groups $(n=54)$.

\begin{tabular}{lccc}
\hline Per-operative findings & \multicolumn{2}{c}{ Groups } & p value \\
\cline { 2 - 4 } & Group A & Group B & \\
\hline $\mathrm{XCT}(\mathrm{min})$ & $52.18 \pm 2.03$ & mean \pm SD & \\
$\mathrm{ECCT}(\mathrm{min})$ & $82.33 \pm 4.42$ & $53.25 \pm 1.48$ & 0.56 \\
\hline
\end{tabular}


Table-VI

Comparison of postoperative PASP outcome between groups $(n=54)$.

\begin{tabular}{lccc}
\hline Postoperative outcome & \multicolumn{2}{c}{ Group } & p value \\
\cline { 2 - 3 } & Group A(n=27) & Group B(n=27) & \\
\hline Postoperative PASP at 7 ${ }^{\text {th }}$ POD & $33.55 \pm 1.23$ & $41.70 \pm 5.60$ & .001 \\
Postoperative PASP at 1 month & $30.55 \pm 2.26$ & $39.11 \pm 3.28$ & .001 \\
\hline
\end{tabular}

Table-VII

Comparison of Postoperative ventilation time and ICU stay $(n=54)$.

\begin{tabular}{lccc}
\hline Per-operative findings & \multicolumn{2}{c}{ Groups } & p value \\
\cline { 2 - 4 } & Group A & Group B & \\
\hline Ventilation time (hours) & $5.96 \pm 0.758$ & mean \pm SD & \\
ICU stay (days) & $3.66 \pm 0.78$ & $11.14 \pm 1.32$ & 0.013 \\
\hline
\end{tabular}

\section{Discussion:}

$\mathrm{PAH}$ is a diverse group of diseases characterized by a progressive increase of pulmonary vascular resistance which leads to right ventricular failure and premature death if untreated. ${ }^{11}$ As the disease progresses and right ventricular after-load increases, the heart's ability to increase cardiac output with activity declines, resulting in exertional dyspnea, chest pain, or syncope. Eventually, progressive right heart dysfunction ensues, leading to right heart failure and death. ${ }^{12}$ VSD is defined as a hole or multiple holes in the interventricular septum. ${ }^{13}$ The conventional definition of PAH used in clinical studies includes an mean pulmonary arterial pressure (mPAP) of greater than $25 \mathrm{~mm}$ of $\mathrm{Hg}$ at rest in the setting of a normal pulmonary arterial wedge pressure of $15 \mathrm{~mm}$ of $\mathrm{Hg}$ or less with a PVR greater than 3 Wood unit. ${ }^{14}$ In a pilot study of acute administration of high doses of ambrisentan to patients with pulmonary hypertension, pulmonary and systemic resistance decreased, suggesting that chronic doses might be necessary for a significant and selective effect. ${ }^{15}$ Considering the preoperative variables like PASP on echocardiogram and on cardiac catheterization, Qp/Qs ratio and PVR were compared between the two groups and there was no significant difference between two groups. There was significant reduction of PASP both before CPB establishment, just after VSD closure and after weaning from CPB in patients who were treated with preoperative oral ambrisentan. In the ambrisentan group XCT was $52.18 \pm 2.03$ minutes and in the control group it was $53.25 \pm 1.48$ minutes. ECCT was $82.33 \pm 4.42$ minutes in ambrisentan group and 87.22 \pm 5.89 minutes in control group. These peroperative findings are similar to the study of Peiravian et al. ${ }^{16} \mathrm{PA}$ pressure is significantly reduced following ambrisentan treatment which corresponds with the findings of both Peiravian et $\mathrm{al}^{16}$ and that of Nemoto et al. ${ }^{17}$ Mechanical ventilation time was significantly ( $p=0.013)$ less $(5.96 \pm .758$ hours $)$ in ambrisentam group than in control group (11.14 \pm 1.32 hours) and this findings corresponds with the study of Peiravian et $\mathrm{al}^{16}$ and that of Nemoto et al. ${ }^{17}$ Reduction of ICU stay and time of ventilating support indicates there is less incidence of development of $\mathrm{RV}$ failure due to pulmonary arterial hypertensive crisis in patients of Group-A receiving oral ambrisentan . Perivian et $\mathrm{al}^{16}$ and Nemoto et $\mathrm{l}^{17}$ performed two studies with oral sildinafil in their studies. The results of our study are similar to them. No patient died during the study period of both the study groups. We used to continue oral ambrisentan for at least two months postoperatively for smooth recovery of the disease. For this reason we could not asses like other studies the rebound pulmonary hypertension following discontinuation of the drug. There were some limitations of our study; it was a single center study with smaller sample size and short term follow up. 


\section{Conclusion:}

In this study it has been found that there is significant reduction in pulmonary hypertension both before and after surgical closure of VSD with the use oral ambrisentan preoperatively. So ambrisentan can be considered as an attractive and effective oral therapy for moderate to severe pulmonary hypertension. It is safe and easy to administer and inexpensive. However further studies are necessary to determine the efficacy, safety and optimal dosing of ambrisentan. Careful long term follow up and conduction of a double blind clinical trial is required to examine the effects of ambrisentan further. Within these limitations we conclude that oral ambrisentan may be advised preoperatively for every patient with VSD with moderate to severe pulmonary hypertension.

\section{Conflict of Interest - None.}

\section{References:}

1. Adatia I, Kothari SS, and Feinstein JA. Pulmonary hypertension associated with congenital heart disease. pulmonary vascular disease: the global perspective. Chest 2010 ;137(1:). 52-61.

2. Kaplan B, Butler H, Krishbom P, Kanter K, Mcconnell M. Closure of symptomatic ventricular septal defects: How early is too early? Pediatric Cardiol 2002;29: 3639.

3. Berger MR, Zisma LS, Lowes BD, Abraham WT, Badesch DB, Groves BM. The pressure-overloaded right ventricle in pulmonary hypertension. Chest 2002;114 (1):101-106.

4. Midany A, Sunnegardh J, Berggren H. Preoperative evaluation and surgery in isolated ventricular septal defects: a 21 year perspective. Heart 2013; 83:198-204.

5. Malouf K, Ihnkem K, Buckberg GD, Sherman MP, Ignore LJ . Pulmonary vasoconstriction due to impaired nitric oxide production after cardiopulmonary bypass. Ann Thorac Surg 2002;61:1775-1778.

6. McLaughlin VV, Genthner DE, Panella MM, Rich S . Reduction in pulmonary vascular resistance with longterm epoprostenol (prostacyclin) therapy in primary pulmonary hypertension. New Engl J Med 1998;338 (5): 273-277.

7. Schlingmann TR, Yu J, Taylor L, Wilson J, Comhair S, Erzurum S, et al. Altered expression and signal transduction of endothelin-1 receptor in heritable and idiopathic pulmonary artery hypertension. $J$ Cell Physiol 2013; 228-229.

8. Nathan B, Vinicio A, deJesus P, Alice R, Francois H, Andre D, et al. Perioperative pharmacological management of pulmonary hypertensive crisis during congenital heart surgery. Pulm Circ 2014; 4(1): 10-24.

9. Yu J, Tayior L, Wilson J, Comhair S, Polgar P. Altered expression and signal transduction of endothelin-1 receptor in heritable and idiopathic pulmonary artery hypertension. J Cell Physiology 2013; 228(2) :322-329.

10. Beghetti M, Tissot C. Pulmonary Hypertension in Congenital Shunts. J Am Col Cardiol 2008 ; 63(10):1179-1193.

11. Simonneau G, Galiè N, Rubin LJ. Clinical classification of pulmonary hypertension. J Am Coll Cardiol 2004; 43 (1): 5-12.

12. Barst DB, Abman SH, Ahearn GS, McCror DC, Simonneau G, McLaughlin VV. Medical therapy for pulmonary arterial hypertension: ACCP evidence-based clinical practice guidelines. Chest 1996; 126(1): 35-62.

13. Kouchoukos NT, Blackstone EH, Hanley FL and Kirklin JK. Ventricular Septal Defect. In: Kirklinn JW, BarrattBoyes BG . Eds. Cardiac Surgery, $4^{\text {th }}$ ed. Philadelphia, Pensilvaneya: Churchill Livingston, 2013: 1274-1326.

14. Yanagiswa H, Yoshitoshi $\mathrm{M}$ and Miyamoto AT. Ventricular septal defect: selection of patient and timing of surgery. Am Heart J 1988; 1:40-50.

15. Richard VM, Carl J L, Andres R. Clinical correlates and reference intervals for pulmonary artery systolic pressure among echo-cardiographically normal subjects. Circulation 2001; 104: 2797-2802.

16. Peiravian F, Amirghofran AA, Borzouee M, Ajami GH, Sabri MR, Kolaee S. Oral Sildenafil to Control Pulmonary Hypertension after Congenital Heart Surgery. Asian Cardiovasc Thorac Ann 2007; 15:113117.

17. Nemoto S, Sasaki T, Ozawa H, Katsumata T, Kishi K, Umegaki O. Oral sildenafil for persistent pulmonary hypertension early after congenital cardiac surgery in children. Eur J Cardio Thorac Surg 2010; 38:71-77. 